\title{
Thermal Analysis and Impart of Temperature Distribution on the Performance of Additive Manufactured Titanium Alloy Based Composite Coatings
}

\author{
O.S. FATOBA ${ }^{1} ;$ S.A. AKINLABI ${ }^{2} ;$ E.A. MEKONEN ${ }^{3}$ B.A. TADESSE ${ }^{3} ; E . T$. AKINLABI $^{4}$ \\ ${ }^{1}$ Department of Mechanical Engineering Science, University of Johannesburg, Johannesburg, South Africa. \\ ${ }^{2}$ Department of Mechanical Engineering, Walter Sisulu University, Butterworth Campus, Eastern Cape, South Africa \\ ${ }^{3}$ Department of Mechanical Engineering, Debre Tabor University, Amhara Region, Debre Tabor, Ethiopia. \\ ${ }^{4}$ Pan African University for Life and Earth Sciences (PAULESI), Ibadan, Nigeria \\ Corresponding author: proffatobasameni@gmail.com*
}

\begin{abstract}
Finite element numerical analysis can be used to solve problems of boundary values. The accuracy of model is depended on the meshing refinement. In aerospace industry, finite element analysis has been used by several researchers to know the influence of temperature distribution on the performance of additive manufactured component parts. Accuracy is better with finer mesh. Complex nature of the additive manufacturing process due to rapid heating and cooling made many researchers to adopt numerical investigation which is made easier than the experimental method. Proper modelling of the process must be thoroughly done for the numerical modelling results to be analyzed. The experiment of ternary titanium alloy of Ti-Al-Si-Cu was carried out with cladding machine of 3000 Watts (CW) Ytterbium Laser System (YLS-2000-TR). This machine is situated at the National Laser Centre in the Council of Scientific and Industrial Research (NLC-CSIR). The characterization was done using the standardization ASTM E3-11 procedure. The results shiw the impart of temperature distribution on the dendritic arm spacing in the microstructures. The rate of cooling imparts on the space between the dendritic arms. The more the space, the more the influence on the coating's properties
\end{abstract}

\section{INTRODUCTION}

The diverse applications and extraordinary properties of titanium alloy in medical and aerospace industries cannot be overemphasized. Some of the properties such as high specific strength, low density, low elastic modulus, good electrochemical resistance, and biocompatibility have been the reason behind the extended applications of titanium alloy in the aerospace, automotive, marine and medical industries [1]. One of the most widely used titanium alloy in the marine and aerospace industries is Ti-6Al-4V alloy [2]. However, despite all these exceptional properties of titanium alloy, the major drawbacks are poor wear resistance and low hardness [3-6].
These drawbacks can be eliminated or enhanced by laser metal deposition of composite coatings on the base titanium alloy. One of the major benefits of additive manufacturing is materials conservation and this reduces the titanium alloy manufacturing cost. Likewise, inaccurate dimensions are avoided through the use of 3D model data in additive manufacturing [7]. Many researchers have tried to modify the surface characteristics of titanium alloy by using composite coatings $[8,9]$. These composites coatings proposed by these researchers were polymer matrix composite, metal matrix composite, intermetallic composite and ceramic matrix 
composite [10]. Other authors had reported laser cladding as the best method of achieving composite coating [11].

The call for advanced and capable technologies has brought about the necessity for innovative manufacturing. The evolving of additive manufacturing has revolutionized many industries based on the principle of producing objects or components by materials addition in layer by layer based on ASTM F24 standardization [12]. The impacts of additive manufacturing have been felt in the manufacturing of complex aerospace components and structures. This has brought about reduction in cost and time in manufacturing materials that are very expensive. Moreover, additive manufacturing has given extended lifespan to used tools [13-15].

Refined, enhanced and dense microstructures, narrow heat affected zone, good bonding, and minute stress deformation were part of the characteristics reported by the researchers that separate laser cladding from other conventional techniques [16-19]. In additive manufacturing, components parts are manufactured layer by layer by using laser energy. However, materials exhibit anisotropic properties, and visible residual stresses. These occur due to phenomena of cooling and thermal non-homogenuity during the additive manufacturing process [20]. The additive manufacturing process mechanism depend solely on rapid heating and solidification of the reinforcement powders deposited [9]. Temperature distribution affects the materials properties during additive manufacturing process. Many researchers have studied the distribution of temperature by different techniques, but numerical modeling is the more dominant investigation method [21-24].

Complex nature of the additive manufacturing process due to rapid heating and cooling made many researchers to adopt numerical investigation which is made easier than the experimental method. Proper modelling of the process must be thoroughly done for the numerical modelling results to be analyzed. Unwanted residual stresses are avoided when the temperature distribution is put in check [20]. The authors had considered the effects of temperature distribution in additive manufacturing and porosity impart on the material's thermal properties. Other researchers placed 4 thermocouples in different parts of the deposited clads by using 2D and 3D finite difference modelling to compare the experimental results data with the numerical modelling [25]. In addendum, Mirkooh et al. [26] compared the experimental method with the analytical and numerical methods in order to analyze the temperature distribution, the authors concluded that analytical method would be better to predict the distribution of temperature due to materials properties temperature sensitivity. This paper mainly focuses on analysis of temperature distribution of Additive Manufactured Titanium Alloy Based Composite Coating and the impart of temperature distribution on the performance of additive manufactured titanium alloy based composite coating.

\subsection{MATERIALS AND METHODS}

The dimension of the base metal (Titanium alloy grade 5) for the cladding process was $74 \times 74 \times 5 \mathrm{~mm}^{3}$. Standard metallographic procedure for microstructural analysis sample preparation was used and the samples were made into $10 \times 10$ $\mathrm{mm}$. Nital reagent was used for the etching and this followed by washing in water and then drying of the sample in air. As soon as the metallographic preparation was done, desiccator was used to store the base metals before the real experiment.

Pure powders of Titanium (Ti) Aluminium (Al), Silicon (Si) and Copper $(\mathrm{Cu})$ were used for this experiment with average particle size of 80 microns. The reinforcement powder used to create the coats composed of a ratio distribution of Al$\mathrm{Cu}-\mathrm{Ti}$ as follows: Al-4Cu-7 Ti (900 W, $0.8 \mathrm{~m} / \mathrm{min}$ ), Al-4Cu-7Ti $(1000 \mathrm{~W}, 1.0 \mathrm{~m} / \mathrm{min}), \mathrm{Al}-7 \mathrm{Cu}-5 \mathrm{Ti}(900 \mathrm{~W}, 0.8 \mathrm{~m} / \mathrm{min}), \mathrm{Al}-7 \mathrm{Cu}-$ $5 \mathrm{Ti}(1000 \mathrm{~W}, 1.0 \mathrm{~m} / \mathrm{min})$ fractions correspondingly. The purity of the powders was $99.9 \%$. Characterization of both powders were done first for microstructural analysis. Shimadzu Analytical balance was used for the weighing of both powders for vital powder mixing. Different weighing proportions of the powders were done accordingly with Tubular mixer at speed of $72 \mathrm{rev} / \mathrm{min}$. Design of experiment (DOE) was used to pick the best parameters during the laser cladding experiment. The following parameters were considered during experiment (diameter of laser beam in $\mathrm{mm}$, laser power in $\mathrm{W}$, gas shielding rate in $\mathrm{L} / \mathrm{min}$, scanning velocity in $\mathrm{m} / \mathrm{min}$, and powder feed rate in $\mathrm{g} / \mathrm{min}$ ). Track overlapping was done at $70 \%$ and Argon being inexpensive, was used as the shielding gas $(2.5 \mathrm{~L} / \mathrm{min})$. This shielding gas was used to avoid oxidation during the experiment. The flowability of the gas depends on the gas density. The powder was spherical in shape $(2.0 \mathrm{~g} / \mathrm{min})$. Lower flow rate of the gas depends on the gas higher density which in turn reduces the velocity of the reinforcements for the cladding process as seen in Figure 1. The base metal was separated from the Laser nozzle head by $2 \mathrm{~mm}$ distance.

The experiment was carried out with cladding machine of 3000 Watts (CW) Ytterbium Laser System (YLS-2000-TR). This machine is situated at the National Laser Centre in the Council of Scientific and Industrial Research (NLC-CSIR).

The most dominating factors during the experiment were scanning velocity and laser power. Varied laser power from $900-1100 \mathrm{~W}$ was used. While $0.8-1.2 \mathrm{~m} / \mathrm{min}$ varied scan velocity was used for the cladding process. The DOE optimization method influences the homogeneous microstructures of the samples with no porosity and cracks. Scanning Electron Microscopy (SEM) was used to view the microstructures of the cladded samples. Likewise, crosssectional view of the cladded samples was also taken into consideration. Grinding and polishing of the cladded samples were done using different grinding papers $(220,660$ and fine ground) on MD-largo diamond disc. Polishing of the cladded surfaces was done using diamond polishing suspensions (6-1 microns) on polishing cloths with observation of a mirror-like surface. Distilled water was used for rinsing of the polished surfaces, acetone degreased and dried. 
The materials characterization desired results were done after the samples had been well polished and reflective. The characterization was done using the standardization ASTM E3-11 procedure. Optical images of the samples were taking via the cross-sectional areas of the samples using the standardization procedure ASTM E2228-10 standard with BX51M Olympus microscope. The microstructural evolution was carried out using the TESCAN machine with an X-MAX instrument with ASTM E766-14e1 standardization procedure.

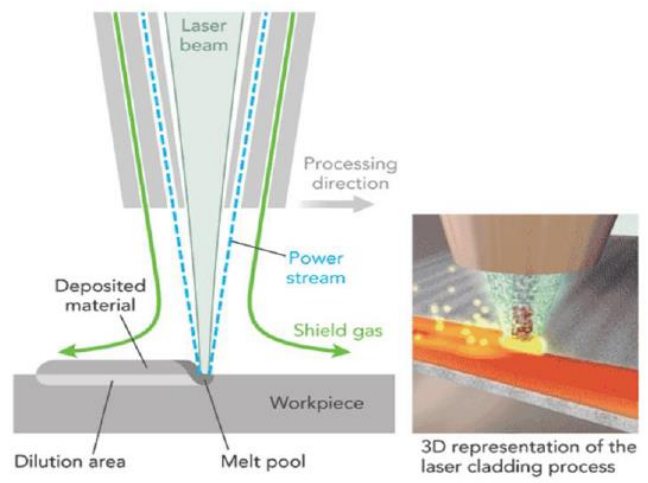

Fig 1: Laser Metal Deposition Machine [27]

\subsection{RESULTS AND DISCUSSION}

\subsection{Numerical Modelling}

The use of COMSOL Multiphysics in confirming the additive manufacturing processes and the validation of the enhanced properties is very crucial. The generation of stresses and temperature distribution validation are part of the way of comparing the experimental work with the numerical modelling. The design was created, and 3D boundaries was used in proving the geometry $\left(\mathrm{d}_{1}, \mathrm{~d}_{2}, \mathrm{k}\right)$. While $\mathrm{k}$ is the normal component, tangential components are stated as $\mathrm{d}_{1}$ and $\mathrm{d}_{2}$. Few assumptions in this model are made in the validation of the experimental work:

1. Convection and radiations heat losses were not considered in this model.

2. The type of flow assumed in this model is incompressible and laminar. The flow follows the Newtonian law.

3. 90 degrees angle position was made between the laser beam and the base titanium alloy. The movement of the laser beam was done in the $\mathrm{z}$-direction.

4. Homogeneity of the base titanium alloy and the powder reinforcements are intact and isotropic.

5. The materials thermo-physical properties came alive by inducement of the temperature.

The heat equations are dependent on time and influenced the solid domains and the initials domains. The initial temperature was $295 \mathrm{~K}$ as shown in the options lists. The below equations are used in the heat transfer equations (Fourier's law) for solid as given in equations 1-3.

$$
\begin{aligned}
& \rho C_{p} \frac{\partial T}{\partial t}+\rho C_{p} u \cdot \nabla T+\nabla \cdot q=Q \\
& \text { or } \quad \frac{\partial p}{\partial t}+\nabla \cdot(\rho \mathbf{v})=0
\end{aligned}
$$

Expression of the integrand $\nabla .(\rho \mathbf{v})$ in cartesian coordinates $\mathbf{v}=(1, \mathrm{~m}, \mathrm{n})$

$$
\nabla \cdot(\rho \mathbf{v})=\frac{\partial(\rho l)}{\partial i}+\frac{\partial(\rho m)}{\partial j}+\frac{\partial(\rho n)}{\partial k}
$$

The representation of solid density $\left[\mathrm{kg} / \mathrm{m}^{3}\right]$ is given by $\rho$, the solid heat capacity (constant pressure) is $C_{p}$, the velocity field is symbolized by $u$, defined by translation motion sub-node when model parts move in the frame of material $[\mathrm{m} / \mathrm{s}]$, heat source $\left[\mathrm{W} / \mathrm{m}^{3}\right]$ is symbolized by $Q$ and the heat flux $\left[\mathrm{W} / \mathrm{m}^{2}\right]$ which is symbolized by $q$ is determined by equation 4 :

$$
q=-k \nabla T
$$

Thermal conductivity $[W / m . K]$ is symbolized by $k$ and the change in temperature $[K]$ is symbolized by $\nabla T$.

The materials thermal conductivity of the base titanium alloy is based on the default material picked $\mathrm{n}$ the model. Heat was prevented from going out from the domain insulation i.e the domain insulation was protected and there was no heat flux. In the condition for the default boundary, there was thermal insulation.

\subsection{Mesh Generation and Geometric Model}

The analyses of the meshing were subject to the varied meshing dimensions thereby making the base titanium alloy well defined as well as the laser track. $0.05 \mathrm{~cm}$ minimal element size was used for the laser track. $0.14 \mathrm{~cm}$ maximal element size was used. $0.18 \mathrm{~cm}$ minimal element size and 0.44 $\mathrm{cm}$ for the maximal element size were used for the base titanium alloy as seen in Figure 4.41. Analysis of meshing produced 55900 nodes and also produced 36642 elements, and this represents the laser metal deposition process experimental simulation. The properties of the base titanium alloy used for the meshing has yield strength of $8.2737 \mathrm{e}^{8} \mathrm{~N} / \mathrm{m}^{2}$, elastic modules of $1.05 \mathrm{e}^{11} \mathrm{~N} / \mathrm{m}^{2}$, poisson ration of 0.32 , tensile strength of $1.1 \mathrm{e}^{9} \mathrm{~N} / \mathrm{m}^{2}$, shear modulus of $4.1 \mathrm{e}^{10} \mathrm{~N} / \mathrm{m}^{2}$, mass density of $4420 \mathrm{~kg} / \mathrm{m}^{3}$, and the base titanium alloy is linear elastic isotropic.

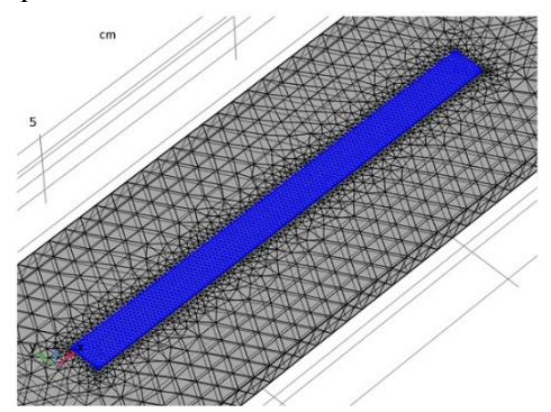

Fig 2: The Mesh System 
$295 \mathrm{~K}$ was used as the initial temperature. Figures 2 and 3 show the base titanium alloy temperature distribution and the quality of meshing of the base titanium alloy design. The base titanium alloy had to be pre-heated in order to know the stresses involved in the base alloy. Uniform distribution of heat is experienced and absorbance of laser heat in the base titanium alloy by pre-heating the base alloy. This pre-heating avoids the drawbacks (poor surface quality) of residual stresses induced by thermal gradient which negatives the microstructures enhancement by increasing the grain sizes. The meshing base titanium alloy was subjected to residual stresses as shown in Figure 4.

The larger the stresses of residual the more the tampering on the load resistance component. Identification of irregularities is very vital and their categorization. Meeting the required standardization and quality control are also very vital. There are various factors that can affect additive manufacturing surface performance and these anomalies must be seriously addressed and well understood. Anomalies can be terms of poor combinations of factors such like direction of build, rate of flow, thickness of layer and scan velocity. The quality of assurance of additive manufacturing has been the main draw-back of this process confronting the aerospace and medical industries. New techniques of predicting and detecting anomalies in additive manufacturing wold improve the quality assurance. The inducement of stresses in additive manufacturing parts comes through the thermal cycle of the additive manufactured metals. Distortion has been one of the disadvantages of this residual stresses inducement when it is not managed well.

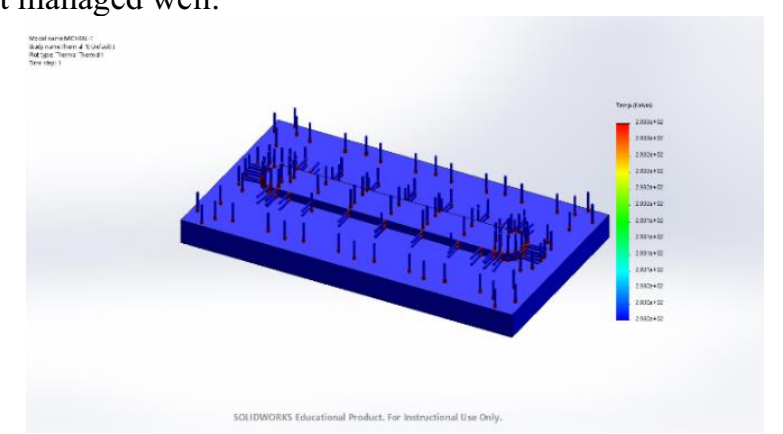

Fig 3: Temperature Distribution on the Base Titanium Alloy at $295 \mathrm{~K}$.

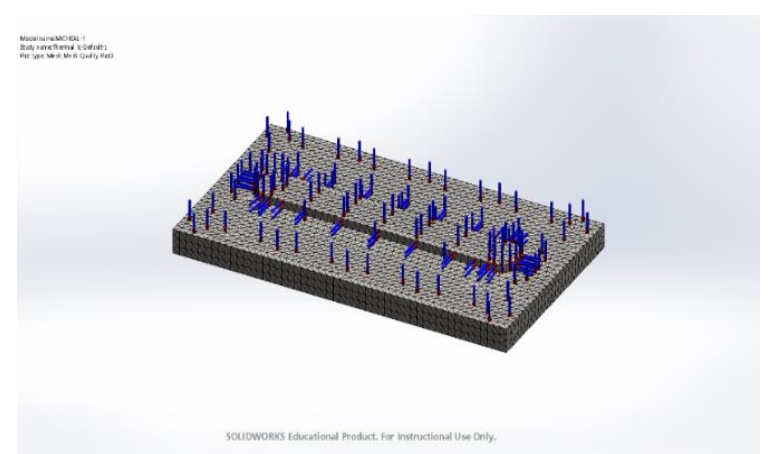

Fig 4: The Mesh Quality at High Temperature

Higher laser power with increased scanning velocity induces molten liquid flow in the melt pool during the laser metal deposition process. Spheroidization, standard distribution and enhancement are generated by the increase in the laser power, and this can be seen in Figures 5-7.

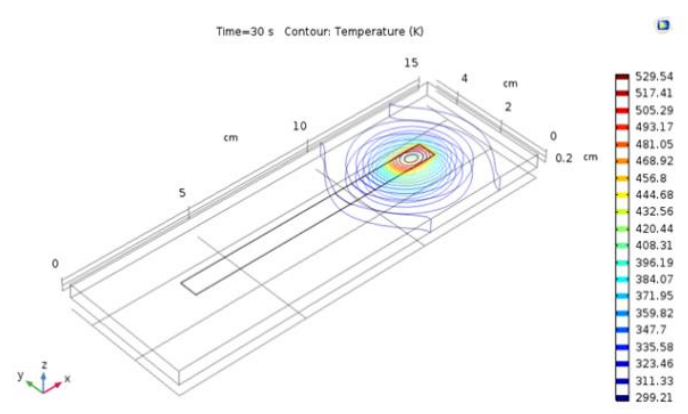

Fig 5: The Contour Plot of Temperature Distribution Results at the Starting Point
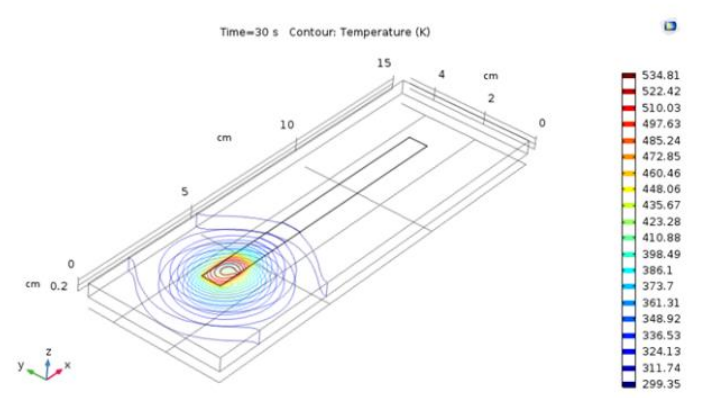

Fig 6: The Contour Plot of Temperature Distribution Results at the End of the Substrate 


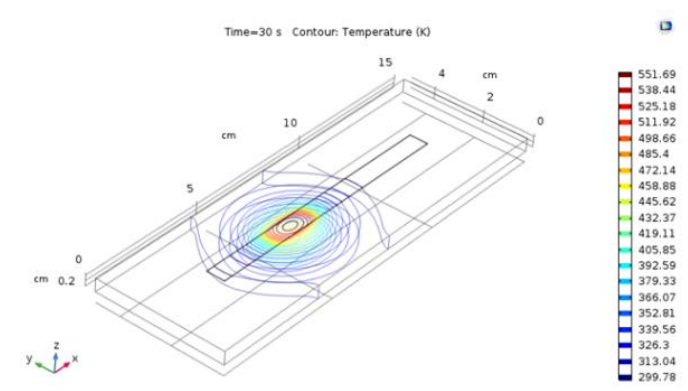

Fig 7: The Contour Plot of Temperature Distribution nearly the middle of the Substrate

The microstructures enhancement is made as the laser moves from one point to the other end point and the temperature distribution in each point changes the microstructure in the melt pool. The changes are due to factors such as scan velocity, laser intensity and faster cooling rate. The absorbance of heat by the base titanium alloy and the difference in temperature between the laser and the base titanium alloy makes a significant difference in the final microstructure produced during the laser metal deposition process. The temperature gradient determines the degree of residual stresses that would be induced and the amount of stresses induced influence the surface quality of the additive manufactured parts and the microstructure. Excesses residual stresses may poorly impart the quality of the components.

The temperature distribution peak in the molten pool is dependent on the distance between laser nozzle and the base titanium alloy including spot diameter. The starting point showed peak temperature of $529 \mathrm{~K}$ and $534 \mathrm{~K}$ at the end of the movement. The microstructures are formed by this temperature distribution and the solidification rate of the molten pool. The coating width went down due to the increased scanning velocity during the process, and this came about as a result of small interaction time between the reinforcement powders and the laser. The opposite was the case when the scanning velocity was decreased because the coating width increased $[28,29]$. The scanning velocity factor really had an effect on the dilution rate of the reinforcement powders in the molten pool. There was decrease in dilution rate as a result of increase in scanning velocity [29].

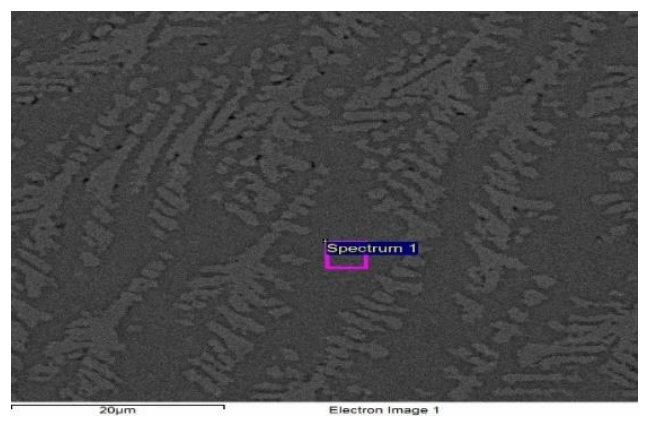

Fig 8: SEM Image of Sample 1 with effect of Temperature Distribution

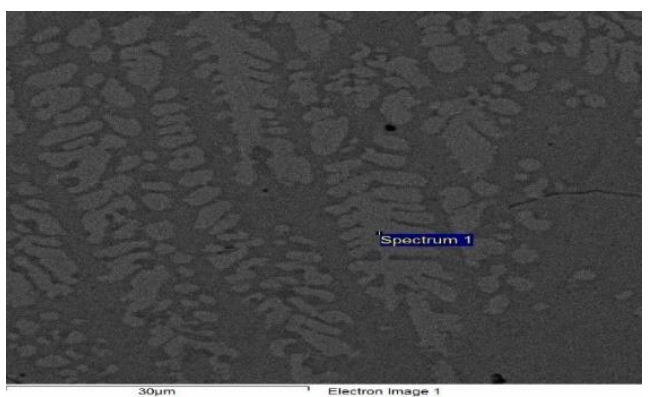

Fig 9: SEM Image of Sample 5 with effect of Temperature Distribution

The solidification process in the microstructure induced the grains propagation during the process in the molten pool. As the reinforcement powders interact with the laser, there are changes in the temperature distribution as the movement of the laser progresses. The propagation of grains starts from the point of interaction between the reinforcement powders and the laser. However, the only evolution that takes place happens between the interaction of the base titanium alloy and molten pool of the reinforcement powders. The understanding of the dilution rate of the reinforcement powders and part of the base titanium alloy is very necessary in order to understand the diffusion of the composite materials in the final microstructure. Dendritic phases are formed by the composite interaction of copper and aluminium in the matrix during the process of solidification process.

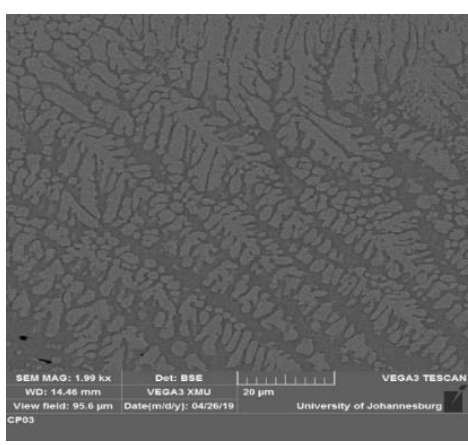

Fig 10: SEM Image of Sample 3 with effect of Temperature Distribution

However, the formation of the dendritic phases majorly depended on the thermal gradient. Copper has a very strong stable beta phase which are propagated during the metal deposition process $[30,31]$. Since the base titanium alloy reacts with the reinforcement copper in the molten pool, betatitanium phase structure $(\beta-\mathrm{Ti})$ was initiated and propagated. Dendritic grain propagation was formed by the aluminiumcopper $(\mathrm{Al}-\mathrm{Cu})$ structures with increased scanning velocity and laser power $[32,33]$. Due to the beta and alpha phases in the base titanium alloy, new formation of structure of eutectic phases and inter-dendritic intermetallics are found in the composites of the coatings. 


\section{CONCLUSIONS}

The inducement of thermal history during the laser metal deposition process activates the alpha and beta transformation from the alpha microstructure initiated in the beginning. The morphologies of the distinct grain undergone evolution and growth and led to the stabilized alpha and beta structures as the structures undergo decrease and increase. Evolution of the microstructure is greatly affected by the distance between the laser nozzle tip and the base titanium alloy surface by creating a molten pool on the base alloy. The molten pool is also influenced by the scanning velocity and the reinforcement powder feed rate. This in turn enhance the microstructures. The rate of cooling imparts on the space between the dendritic arms. The more the space, the more the influence on the coating's properties

\section{Acknowledgements}

The authors wish to acknowledge Pan African University for Life and Earth Sciences (PAULESI), Ibadan, Nigeria for the funding and National Laser Center, CSIR South Africa for the laser equipment.

\section{REFERENCES}

[1] Liu, S. S., Wang, X. H., Zhang, M., \& Zhao, G. L., 8(6), 5930 (2019)

[2] Phutela, C., Aboulkhair, N. T., Tuck, C. J., \& Ashcroft, I., Materials, 13(1), 117 (2020)

[3] Fatoba O.S., Adesina O.S. Popoola A.P.I., The International Journal of Advanced Manufacturing Technology. 97(5), 2341 (2018)

[4] Fatoba O.S., Akinlabi S.A., Gharehbaghi R. \& Akinlabi

E.T., Materials Express Research. 5(6), 1 (2018)

[5] Fatoba, O. S., Akinlabi, E. T., \& Akinlabi, S. A., (ICMIMT 2018), 74 (2018)

[6] Fatoba O.S; Akinlabi, E.T. \& Makhatha, M.E., Materials Today: Proceedings. 5 (9), 18368 (2018)

[7] Mirkoohi, E., Ning, J., Bocchini, P., Fergani, O., Chiang, K. N., \& Liang, S. Y., Journal of Manufacturing and Materials Processing, 2(3), 63 (2018)

[8] Yadav, S., Kumar, A., Paramesh, T., \& Sunita, K., Materials Science and Engineering 455(1), 012120 (2018)

[9] Pham, N. T. H., \& Nguyen, V. T., Wear properties of TiCreinforced Co50 composite coatings from room temperature to high temperature. Advances in Materials Science and Engineering, (2020)

[10] Huang, C. C., Li, H. M., Li, D. H., \& Lin, S. Y., Composites and Advanced Materials, 30, 2633366X20974686. (2021)

[11] Shi, Q., Zhu, H., \& Li, C., Coatings, 10(5), 498 (2020)

[12] du Plooy, R., \& Akinlabi, E. T., Materials Today: Proceedings, 5(9), 19594 (2018)

[13] Lipson, H., \& Kurman, M., Factory@ home: The emerging economy of personal fabrication. A report commissioned by the US Office of Science and Technology Policy (2010)

[14] Huang, S. H., Liu, P., Mokasdar, A., \& Hou, L., The International Journal of Advanced Manufacturing Technology, 67(5), 1191 (2013)

[15] Antoniw, S., McCarthy, N., Pacey, E., Parkin, B., \& Shelton, P., Additive manufacturing: opportunities and constraints. Royal Academy of Engineering, 1st edition, London (2013)

[16] Fiołek, A., Zimowski, S., Kopia, A., Sitarz, M., \& Moskalewicz, T., Metallurgical and Materials Transactions A, 51(9), 4786 (2020)

[17] Obiegbu, M. C., Fatoba, O. S., Akinlabi, E. T., \& Akinlabi, S. A., Materials Research Express, 6(4), 046552 (2019)

[18] Fatoba, O. S., Akinlabi, S. A., \& Akinlabi, E. T., (ICMIMT-2018) 85 (2018)

[19] Gharehbaghi, R., Fatoba, O. S., \& Akinlabi, E. T., (ICMIMT-2018) 44 (2018)

[20] Foteinopoulos, P., Papacharalampopoulos, A., \& Stavropoulos, P., CIRP Journal of Manufacturing Science and Technology, 20, 66 (2018)

[21] Fatoba, O. S., Akinlabi, E. T., Akinlabi, S. A., \& Obiegbu, M. C., Data in brief, 23, 103724 (2019)

[22] Gharehbaghi, R., Akinlabi, E. T., \& Fatoba, O. S. (ICMIMT) 31 (2018)

[23] Fatoba, O. S., Akinlabi, E. T., \& Akinlabi, S. A., In Journal of Physics: Conference Series 4(1378), 042040 (2019)

[24] Fatoba, O. S., Akinlabi, E. T., Akinlabi, S. A., \& Krishna, S., Materials Today: Proceedings, 18, 2859 (2019)

[25] Fetni, S., Enrici, T. M., Niccolini, T., Tran, H. S., Dedry, O., Duchêne, L., ... \& Habraken, A. M., Materials \& Design, 204, 109661 (2021)

[26] Mirkoohi, E., Ning, J., Bocchini, P., Fergani, O., Chiang, K. N., \& Liang, S. Y., Journal of Manufacturing and Materials Processing, 2(3), 63 (2018)

[27] Azam, F. I., Rani, A. M. A., Altaf, K., Rao, T. V. V. L. N., \& Zaharin, H. A., In IOP Conf. Ser. Mater. Sci. Eng. 328, 012005 (2018)

[28] D.R. Waryoba, J.S. Keist, C. Ranger, T.A. Palmer., Materials Science \& Engineering A, 734, 149 (2018)

[29] R.M. Mahamood, E.T. Akinlabi, M. Shukla and S. Pityana., International Journal of Mechanical, Industrial science and Engineering, 2, 18 (2012)

[30] Narayana, P. L., Lee, S., Choi, S. W., Li, C. L., Park, C. H., Yeom, J. T., ... \& Hong, J. K., Journal of Alloys and Compounds, 811, 152021 (2019)

[31] Tan, X. P., Chandra, S., Kok, Y., Tor, S. B., Seet, G., Loh, N. H., \& Liu, E., Materialia, 7, 100365 (2019)

[32] Huang, H., Ding, H., \& Xu, X., Procedia Manufacturing, 37, 73 (2019)

[33] Chlupova, A., Heczko, M., Obrtlík, K., Dlouhý, A., \& Kruml, T., Materials Science and Engineering: A, 786, 139427 (2020) 